\title{
Transformation of the Assessment of the Quality of Educational Activities and Training of Future Science Teachers in the Context of the Pandemic
}

\author{
Elena A. Khodyreva ${ }^{1,2^{*}}$, Aydar M. Kalimullin ${ }^{3}$, Marina R. Zheltukhina ${ }^{4}$, Nina V. Chizh ${ }^{5}$ \\ ${ }^{1}$ Department of Pedagogy, Vyatka State University, Kirov, RUSSIA \\ ${ }^{2}$ Innopolis University, Innopolis, RUSSIA \\ ${ }^{3}$ Institute of Psychology and Education, Kazan Federal University, Kazan, RUSSIA \\ ${ }^{4}$ Volgograd State Socio-Pedagogical University, Volgograd, RUSSIA \\ ${ }^{5}$ Department "Russian Medical Museum", N.A. Semashko National Research Institute of Public Health, Moscow, RUSSIA
}

Received 25 March 2021 - Accepted 17 June 2021

\begin{abstract}
The article proposes the concept of transformation of the assessment of the quality of educational activities and the training of future science teachers, the main ideas of which are the objectivity of the assessment; its complex nature; the technological nature of the assessment procedures; their openness; the unity of normative and "non-normative" criteria. It is established that the transformation of the assessment of the quality of educational activities and the training of future science teachers necessitate a comprehensive transformation of its content, instrumental and technological characteristics. The technology of transformation of the assessment of the quality of educational activities and the training of future science teachers in the context of the pandemic has been developed, which involves the implementation of three interrelated stages preparatory, main and final. Its implementation will ensure the adaptation of the assessment of the quality of educational activities to the changed conditions of education; the formation of the subject position of the student in the conditions of informatization of educational activities; improving the quality of professional education by individualizing the content of the assessment of the educational activities of future science teachers, as well as the variability of the assessment procedures used in its implementation. On the basis of expert assessments, proposals for the transformation of the assessment of the quality of educational activities and the training of future science teachers are formulated. Their implementation will allow not only to quickly identify problems in the content and procedural aspects of professional education of future science teachers, but also to timely determine the directions for improving its conditions.
\end{abstract}

Keywords: evaluating the quality of educational activities, future science teachers, the transformation of the content and quality assessment procedures; internal and external systems of quality assessment of educational activities and training

\section{INTRODUCTION}

The relevance of the problem under study is due to the need to identify effective approaches to the content and procedures for assessing the quality of educational activities and training of future science teachers in the changed conditions of the implementation of educational programs of higher education (Abualrob, 2019; Georgiou et al., 2020; Khodyreva, 2020; Levina et al., 2019; Ruban et al., 2020; Sokolovskaya, 2020; Usak et al., 2020), in which the subjects and objects of vocational education are distanced from each other; the content of vocational education is mastered using specific educational services and resources; forms and methods of training are based on the use of information and communication technologies (Abramova \& Antonova, 2020; Domjanić Drozdek et al., 2020; Galchenko et al., 2020; Gimaliev et al., 2020; Kvon et al., 2018; Okhlupina, 2020; Smirnova, 2020; Subocheva, 2020; Tugun et al., 2020; Weindorf-Sysoeva \& Klyagin, 2020).

(C) 2021 by the authors; licensee Modestum. This article is an open access article distributed under the terms and conditions of the Creative Commons Attribution License (http://creativecommons.org/licenses/by/4.0/).

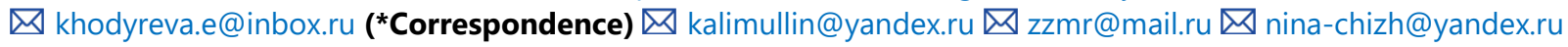




\section{Contribution to the literature}

- The article proposes the concept of transformation of the assessment of the quality of educational activities and the training of future science teachers.

- It is established that the transformation of the assessment of the quality of educational activities and the training of future science teachers necessitate a comprehensive transformation of its content, instrumental and technological characteristics.

- The technology of transformation of the assessment of the quality of educational activities and the training of future science teachers in the context of the pandemic has been developed, which involves the implementation of three interrelated stages - preparatory, main and final.

- On the basis of expert assessments, proposals for the transformation of the assessment of the quality of educational activities and the training of future science teachers are formulated.

This circumstance makes it necessary to transform the assessment of the quality of educational activities and the training of future science teachers as a complex activity of educational subjects, which involves determining, using diagnostic and evaluation procedures, the degree of compliance of students ' educational activities with regulatory requirements, social and personal expectations of future specialists (Permyakov, 2005). When developing diagnostic tools and technologies for assessing the quality of educational activities and training, it is important to take into account not only the specifics of the competence of the future science teacher, including content (availability of special knowledge); technological (knowledge of teaching methods of natural science disciplines); personal (personal qualities) components, but also the features of their manifestation in the context of a significant transformation of the educational process at the university during the pandemic, when the problems of inclusion in the professionalizing activities of future science teachers become particularly relevant (Latysheva et al., 2020; Potapova et al., 2018). The transformation of the methodology, criteria and procedures for assessing the quality of educational activities and training of future science teachers will allow us to quickly make adequate management decisions, ensure timely modernization of the content and procedural aspects of professional education and improve its material, technical, informational, personnel and other conditions.

\section{Purpose and Objectives of the Study}

The purpose of the study is to substantiate the concept and technology of transformation of the quality assessment of educational activities and training of future science teachers in the context of the pandemic.

The following tasks were solved during the study:

1. to substantiate the concept of transformation of the quality assessment of educational activities and training of future science teachers on the basis of competence-based and personality-oriented approaches;

2. to propose a technology for transforming the assessment of the quality of educational activities and the training of future science teachers at the university, which ensures the adaptation of the content, instrumental and technological characteristics of the assessment of the quality of educational activities to the changed conditions of education;

3. to develop recommendations for the transformation of the assessment of the quality of educational activities and the training of future science teachers in the content, technological and instrumental aspects.

\section{LITERATURE REVIEW}

As the analysis of the scientific literature shows, the theory of education quality assessment has formed a systematic understanding of the essence and principles of assessing the quality of educational activities and training of students, its functional structure and procedures (Ali \& Shastri, 2010; Khodyreva, 2020; Kvon et al., 2019; Permyakov, 2005; Razumovskaya et al., 2018; Ruban et al., 2020; Shinkevich et al., 2020; Yermilova et al., 2019). Assessment of the quality of educational activities and training of future science teachers is considered as a complex activity of educational subjects associated with the determination of the degree of compliance of students' educational activities with regulatory requirements, social and personal expectations of future specialists using diagnostic and evaluation procedures.

In research its importance is associated with providing objective and reliable data for the sustainable development of the university in a rapidly changing environment (Barmatina \& Varakuta, 2020). In the context of digitalization the research focuses on the development of models for managing the quality of the educational process in the context of the digitalization of the economy, as well as on the use of digital methods and tools for the development of the educational environment (Apevalova et al., 2018; Golovina \& Alexandrova, 2020; Trapitsin et al., 2017; Zheltukhina et al., 2016).

Researchers agree on the need to establish general principles for assessing the quality of educational activities and training, among which they highlight 
institutional openness, informational openness, regularity, adequacy, consistency and involvement of employers (Barmatina \& Varakuta, 2020), principles of development, integrity, communication, coordination (Lyfenko \& Savchenko, 2017); principles of balance of applied technologies and models, focus on selfdevelopment, individualization, continuity at the levels of education, complexity, transparency and "openness, objectivity, efficiency" (Safronova et al., 2020); ideas of reliability, unambiguity, economy, comparability, timeliness and regularity, uniqueness, objectivity, predictability, adequacy and accuracy (Lachkova \& Pautova, 2016).

Scientists consider the specifics of assessing the quality of educational activities and training of future science teachers in the implementation of individual components of the educational program, including practical training (Trškan, 2017); justify the role of educational subjects in this process (ChigovskayaNazarova, 2017).

The research analyzes the role of inter subject relations, as well as the use of mathematical modeling in the development of the content of assessment funds; the importance of assessing the competencies of future science teachers in the course of solving applied problems, performing research and design work on the history of mathematics, combinatorics, logic is justified.; using the potential of interactive museums, natural science projects on Internet portals and social networks and participation in professional mathematical online communities in evaluation procedures (Arzhakova and Egorova, 2021; Bodryakov \& Voronina, 2018; Larionova et al., 2018; Linnik et al., 2020). Of particular interest is the development of a set of tasks for assessing the quality of research activities of future science teachers. To assess the quality of educational activities and the training of future science teachers, it is necessary to use more widely the potential of professional competitions, including the competition of science teachers "Knowledge-is the power", implemented in the Russian Federation within the framework of the national project "Education". A special place in the evaluation procedures should be occupied by the performance of future science teachers of applied tasks, including those developed by professional associations (in Russia- this is the National Association of Science Teachers, which ensures the interaction of science teachers, accumulates advanced scientific knowledge and innovative educational technologies).

In the context of the spread of COVID-19 coronavirus infection, the research focuses on the need to integrate new elements of assessing the quality of educational activities and training of students related to the conditions of distance (electronic) learning and the traditional assessment system (Smirnova, 2020). Indeed the pandemic transformed the "functional field of activity" of higher education (Abramova, 2020), when both students and teachers needed to master new models and technologies of vocational education in a short time. We agree with the position of researchers Abramova and Antonova (2020), Okhlupina, (2020), Sokolovskaya, (2020), who believe that the model of online education implemented during the COVID-19 pandemic can be considered as risky, capable of influencing the subjective characteristics of students assessment of the quality of educational activities and training. At the same time it was found that the educational environment with a low level of quality (the lack of electronic equipment on self-isolation, necessary for providing distance learning) and unsettled contacts with teachers and classmates, negatively affects the satisfaction with the quality of distance professional education. The researchers Grunt et al. (2020) also stated that the fact of a decline in the quality of education with a total transition to remote work in the context of a pandemic is a challenge for $62,7 \%$ of the respondents studying at universities. Among the most significant risks they indicate a decrease in interest in studying in a remote format; a decrease in satisfaction with the conditions of remote work, unwillingness to master new software products designed for remote access to educational resources, dissatisfaction with relationships with classmates and with teachers, during the assessment of the quality of educational activities; formalization of assessment, which reduces the level of claims in professional activities, when students prefer high grades, rather than the work performed; low satisfaction with working conditions; insufficient level of professional responsibility of teachers for the quality of assessment tools and technologies of their application; detachment of potential employers from the procedures for assessing the quality of educational activities, etc. training of future science teachers.

The identification of such risks and their systematic analysis allowed us to explore the issues of developing and updating methodological techniques and specific pedagogical technologies that can be used to assess the quality of educational activities and training of future science teachers (Okhlupina, 2020; Ruban et al., 2020; Vaindorff-Sysoeva, Klyagin, 2020). These studies are focused on the development of digital tools for presenting the results of educational activities in resource chats of webinars, forums, social networks, on You Tube, using the built-in tools of distance education systems. Innovative forms of presentation of educational results are considered: video recordings of student presentations posted on conference portals; a list of events attended with recorded registration facts (certificate of participation), an annotated list of references posted on the educational forum from the online library, active links to online events conducted by the future science teacher, which allow analyzing the digital traces of students. In conditions when the work is open, fixed, the involvement of students in the 
evaluation procedures increases. That is why researchers pay attention to the need to analyze their own digital traces left on any digital tools during the assessment of the quality of educational activities and training of future teachers.

In general, the review of scientific research made it possible to conclude that certain aspects of the transformation of the assessment of the quality of educational activities and the training of future science teachers are considered quite deeply and comprehensively. The proposed approaches to assessing the quality of educational activities and training of students undoubtedly ensure the improvement of the processes of the university's management system, create conditions for the introduction of innovative assessment tools, but there is a need to develop a holistic concept and technology for transforming the quality assessment of educational activities and training of future science teachers.

\section{METHODOLOGY}

Our research allowed us to develop approaches to assessing the quality of educational activities and training of future teachers based on the concept, the theoretical foundations of which were competencebased and personality-oriented approaches.

From the standpoint of these approaches the transformation of the assessment of the quality of educational activities and the training of future science teachers in the context of a pandemic is considered in the study as the transformation of a set of organizational and functional structures; norms and rules; diagnostic and evaluation procedures that reflect the degree of compliance of the course and results of educational activities implemented in the new conditions with regulatory requirements, as well as social and personal expectations of future specialists.

Based on the essence of the transformation of the assessment of the quality of educational activities and the training of future science teachers, it is possible to determine the purpose and objectives of this activity, among which the following can be distinguished:

- ensuring the adaptation of the content, instrumental and technological characteristics of the assessment of the quality of educational activities to the changed conditions of education;

- formation of the subject position of the student in the conditions of informatization of educational activities, its transition to the use of information and communication educational technologies, including elearning and distance learning technologies;

- improving the quality of professional education by individualizing the content of the assessment of the educational activities of future science teachers, as well as the variability of the evaluation procedures used in its implementation.

We will highlight the conceptual ideas, the implementation of which will ensure the effectiveness of the course and results of the transformation of the assessment of the quality of educational activities and the training of future science teachers, among which the following are the basic ones:

- objective assessment of the quality of educational activities, due to the digitalization of its content and technologies, which makes it possible to obtain reliable results of professional education and make adequate management decisions to improve the professional training of future science teachers;

- comprehensive assessment of the quality of educational activities and training of future science teachers, ensuring the collection, structuring, storage and operational use of the results of the assessment by all interested subjects of professional education;

- the technological nature of the procedures for assessing the quality of educational activities and the training of future science teachers, associated with the need to standardize its conditions and procedures in the electronic information educational environment of the university, as well as requiring the presence of clearly defined criteria and indicators used by the assessment subjects;

- openness of assessment procedures, which requires the use of diagnostic materials available both on the internal resources of the electronic information and educational environment, and on external educational resources, as well as requiring the involvement of all interested subjects of professional education in the assessment procedure;

- the unity of the normative criteria for the quality of educational activities, determined by the requirements of the federal state educational standards in the field of training "Teacher Education" and the "non-normative" criteria declared by consumers of educational services, as well as the requests of specific educational organizations.

The transformation of the assessment of the quality of educational activities and the training of future science teachers necessitates a comprehensive transformation of its content, instrumental and technological characteristics.

The technology of transformation of the assessment of the quality of educational activities and the training of future science teachers in the context of the pandemic is considered by us as a step-by-step sequence of purposeful actions of educational subjects to determine, using diagnostic and evaluation procedures, the degree of compliance of educational activities and the results of training of students with the specified regulatory 
requirements, as well as social and personal expectations.

The purpose of the presented technology is related to the transformation of the content, forms and methods of assessing the quality of educational activities and training of future science teachers through the use of digital educational services and resources in diagnostic and evaluation procedures, as well as relevant information and communication technologies implemented during the current control, intermediate and final certification, as well as assessment of the conditions for the implementation of educational activities.

The technology of transformation of the assessment of the quality of educational activities and the training of future science teachers involves the implementation of three interrelated stages - preparatory, basic and final.

At the preparatory stage the main task is to determine the regulatory, technical and subjective capabilities and limitations for the transformation of the assessment of the quality of educational activities and the training of future science teachers.

Regulatory opportunities and limitations are due to the need to implement the requirements of the federal state educational standards of higher education (FSES for $\mathrm{HE}$ ) to assess the quality of educational activities and training of future science teachers. Summarizing the requirements of the updated FSES for HE in this aspect, it should be noted that the assessment of the quality of educational activities and training of future science teachers should be carried out within the framework of an internal assessment system, as well as within the framework of an external assessment system. The peculiarity of conducting an internal assessment of the quality of educational activities and training of students, as defined by the FSES for HE, should be the participation in its procedures of employers, other legal entities and individuals, as well as teaching staff of universities. The FSES for HE establishes that within the framework of the internal system for assessing the quality of educational activities, students can participate in the assessment of the conditions for the implementation, content, organization and quality of the educational process as a whole, and its individual disciplines (modules) and practices.

When determining the technical possibilities of transforming the assessment of the quality of educational activities and training of future science teachers, it is necessary to take into account the requirements established by the FSES for HE for the electronic information and educational environment as a set of information and educational resources, as well as appropriate technical means that ensure the implementation of the goals of professional education in a particular educational organization. At the same time e-learning services and e-learning resources are the key components of the system, which we consider as the basis for the transformation of quality assessment procedures.

The subject opportunities and limitations for the transformation of the assessment of the quality of educational activities and the training of future science teachers are associated with the change in the ways of involving the subjects of professional education in the assessment procedures in the conditions of the restriction of "direct contacts", requiring them to use special means of communication, as well as specific diagnostic tools.

At the main stage the task consists in the comprehensive implementation by the subjects of the assessment of the normative, technical and subjective capabilities and limitations of the transformation of the assessment of the quality of educational activities and the training of future science teachers, which allows them to jointly determine the specifics of the transformation of the content, instrumental and technological characteristics of the assessment.

It should be noted that these aspects of the transformation of the assessment of the quality of educational activities and the training of future science teachers are implemented comprehensively. They assume the following positions:

- clarification of the list of competencies that are the educational results of the development of the main professional educational program, which characterize the requirements for the future professional activity of the graduate;

- development of evaluation tools based on a comprehensive analysis of the labor functions established by the Professional Standard of a general education teacher, which should be performed by future science teachers, determination of indicators of achievement of competencies established by the FSES for $\mathrm{HE}$, as well as those formed by educational organizations;

- updating the requirements for personnel, information and methodological and other conditions for the implementation of educational activities that are most significant during the pandemic;

- implementation of a comprehensive analysis and ensuring the implementation of the capabilities and resources of the electronic information educational environment of an educational organization for conducting evaluation activities;

- justification and implementation of assessment procedures using digital educational resources and relevant information and communication technologies that are components of the electronic information educational environment of the university.

At the final stage the task is determined by the need to analyze the effectiveness of the transformation of the 
assessment of the quality of educational activities and the training of future science teachers. Two groups of indicators are considered as the main indicators of the effectiveness of this process. The first group includes indicators related to the validity and reliability of diagnostic tools used to assess the quality of the course and results of professional education of a future science teacher, which allow us to assess the level of formation of universal, general professional and professional competencies that ensure the implementation of the main types of professional activities established by the Professional standard of a general education teacher. The second group includes indicators that characterize the quality of the electronic information educational environment as a set of digital educational services and digital educational resources used to assess the quality of educational activities and training of future science teachers - its functionality, flexibility, adaptability, efficiency, reliability.

\section{RESULTS}

In the course of the empirical study a set of methods was used, the leading of which were benchmarking methods, which involved the analysis, evaluation and adaptation of the best practices for assessing the quality of educational activities and training of future science teachers in educational institutions of higher education that implement educational programs in the areas of training related to the enlarged group "Education and pedagogical sciences" in the context of the pandemic; expert methods that allowed us to formulate proposals for improving the content and procedures for assessing the quality of educational activities of future teachers when they master bachelor's and master's degree programs in the context of transformation.

To analyze the best practices of assessing the quality of educational activities and training of future science teachers in educational institutions of higher education that implement educational programs in the areas of training related to the enlarged group "Education and pedagogical sciences", an analysis of information posted by 12 educational organizations participating in the project "Best educational programs of innovative Russia" was conducted (https://akvobr.ru/luchshie_obrazova

telnye_programmy.html) on special sections of official websites dedicated to the prevention of coronavirus infection, as well as to the organization and transformation of the educational process in the context of a pandemic. It is established that on the basis of the normative legal acts in the field of education regulating the state policy and measures of influence in the field of education in extreme situations, each educational organization has developed and posted on the official website on the Internet local normative documents regulating both the features of the educational process in the context of the pandemic in general, and regulating the assessment of the quality of educational activities and training of science teachers in particular.

Based on the analysis of local regulations news information posted in special sections of the official websites of these organizations, it was found that in the practice of assessing the quality of educational activities and training of future science teachers in these Universities, three key approaches to the process of assessing the quality of educational activities and training of students were implemented - synchronous, asynchronous and mixed (see Table 1).

The synchronous approach assumes that the implementation of evaluation procedures is associated with the simultaneous presence of both the teacher and students in the electronic information and educational environment, when the tasks for the current control and intermediate certification and the evaluation procedures are implemented simultaneously, including using proctoring mechanisms. When using this approach to assessing the quality of educational activities and training of future science teachers, a set of electronic educational services and electronic educational resources is used, including Zoom, Office365 cloud services-MSTeams, Skype, Universities' own online learning platforms (Sakai, OpenEdx), etc., which ensure the presence of the teacher and students on the same site at the same time and make it possible to quickly assess the progress and results of educational activities of future science teachers.

The asynchronous approach is associated with the implementation of the ability to perform evaluation procedures without the simultaneous presence of professional education subjects in the electronic information and educational environment. In this approach the teacher loads the tasks for the current control and intermediate certification, and the studentsthe results of their performance. The evaluation procedure is delayed. The implementation of this approach is usually associated with the use of external and internal electronic educational services and electronic educational resources. Internal systems include electronic learning support systems (LMS), including those implemented on the basis of MOODLE, system 1-C: University, electronic library systems of Universities (ELS). External - (national portal "Open Education", Coursera) include online platforms that allow students to organize and control their independent work, as well as to record and store the results of the development of specific disciplines (modules) by future science teachers.

The mixed approach to assessing the quality of educational activities and training of future science teachers, as shown by the analysis, is dominant and assumes that the use of evaluation tools is preceded and accompanied by teacher consultations on the content of 
Table 1. The main approaches to the process of assessing the quality of educational activities and training of future science teachers, implemented in the practice of Universities during the pandemic

Approaches to assessing the Characteristics of approaches to assessing the quality of E-learning services and e-learning quality of educational activities educational activities and training of students resources used for assessment and training of students Synchronous approach

$\begin{array}{ll}\text { The implementation of evaluation procedures is associated } & \text { Zoom, Office365 cloud services - } \\ \text { with the simultaneous presence of a teacher and students in } & \text { MSTeams, Skype, Universities ‘ } \\ \text { the electronic information and educational environment. } & \text { own online learning platforms } \\ \text { Task execution and evaluation procedures are } & \text { (Sakai, OpenEdx) }\end{array}$
implemented simultaneously, including using proctoring mechanisms

Asynchronous
approach $\begin{aligned} & \text { procedures without the simultaneous presence of } \\ & \text { professional education subjects in the electronic } \\ & \text { information and educational environment. } \\ & \text { The evaluation procedure is delayed }\end{aligned}$

Mixed approach
The use of evaluation tools is preceded and accompanied
by teacher consultations on the content of evaluation
materials and evaluation technologies and other
information systems
The ability to obtain timely information about the progress
and results of professional education of future teachers,
about the conditions for its implementation, as well as
provide timely collection and storage of information about
the quality of educational activities and training in general
Electronic learning support systems (LMS), including those implemented on the basis of MOODLE, system 1-C University, electronic library systems of universities (ELS).

National portal "Open Education", Coursera, online platforms

Intra-university electronic learning support systems (LMS), educational process management system " $1 \mathrm{C}$ :

University" (subsystems "Personal account"; "Calendar"; "Courses", "News Forum", "Messaging")

National portal "Open

Education", Coursera, online platforms evaluation materials and evaluation technologies. As the analysis showed, intra - university electronic learning support systems (LMS), in which teachers uploaded materials and tasks, and students-the results of their implementation, within the electronic information and educational environment, as a rule, are associated with the educational process management system "1C: University" (subsystems "Personal account"; "Calendar"; "Courses", "News Forum", "Messaging") and other information systems that provide an opportunity to receive prompt feedback on the progress and results of professional education training of future science teachers, on the conditions of its implementation, as well as provide timely collection and storage of information about the quality of educational activities and the training of future science teachers in general.

It is established that significant attention in the implementation of the above models is paid to the use of electronic educational services and electronic educational resources, both general-purpose and specific, due to the specifics of the subject content of natural science training. At the same time, when selecting the above-mentioned services for assessing the quality of educational activities and training future science teachers, priority was given to those electronic services and electronic resources that were widely used during the pandemic to assess the quality of educational activities and natural science training of students in general education. The use of such services as Google Forms, Yandex Forms, Quiz, Kahoot, Wiser, Padlet, Skysmart makes it possible to conduct surveys, tests and quizzes, and allow you to create evaluation tools of nonstandard formats; to practice the sequence of actions in an interactive mode; to provide the use of digital counterparts of traditional formats of intellectual games.

According to the study the implementation of these approaches in the practice of assessing the quality of educational activities and training future science teachers, made it possible to adapt the content, instrumental and technological characteristics of assessing the quality of educational activities on the basis of modernization of the funds of evaluation tools, changes in evaluation technologies focused mainly on the use of electronic educational services and resources.

However according to a survey of 25 experts involved in the implementation of educational programs in the areas of training belonging to the enlarged group "Education and pedagogical sciences", the transformation of the assessment of the quality of educational activities of future science teachers during the pandemic had significant risks (see Table 2).

The identification of risks allowed us to classify them into three main groups that characterize the problems of the content, instrumental and technological aspects of assessing the quality of educational activities and training future science teachers. 
Table 2. Characteristics of risks of assessing the quality of educational activities and training of future science teachers during the pandemic

Characteristics of the risks of transformation of the assessment of the quality of educational activities of future science teachers during the pandemic

The percentage of experts who pointed out this problem, in \%

The content aspect of the transformation of the assessment of the quality of educational activities and the training of future science teachers

Incompleteness and one-sidedness of the evaluation tools available in the electronic information and educational environment that do not allow a comprehensive assessment of the results of vocational education

Insufficient efficiency of the system content filling of the electronic information and educational environment, designed to assess the formation of competencies

The resources of the electronic information and educational environment are insufficient for timely and qualitative assessment of the quality of educational activities and training of future science teachers

Educational and methodological support (assessment funds) does not provide for the possibility of using e-education and distance learning technologies in the course of assessment procedures

Insufficient quality of electronic educational resources that provide the presentation of assessment tools in electronic and digital form

A large number of tasks for evaluation

Instrumental aspect of the transformation of the assessment of the quality of educational activities and training of future science teachers

Difficulties in the use of special means of communication by subjects of professional education

Restriction of "direct" contacts of educational subjects

Insufficient digital competence of quality assessment subjects

Technical problems in the implementation of the assessment using electronic educational resources

The complexity of the choice of electronic educational services that ensure the implementation of assessment procedures

The technological aspect of the transformation of the assessment of the quality of educational activities and the training of future science teachers

Formalism of monitoring and evaluating students' activity in the classroom, including through their digital footprints

"Anonymity" of the online environment, when teachers do not see the faces and reactions of students

Lack of feedback that prevents adequate assessment of the quality of assimilation of the material and prompt correction

Minor involvement of individual students in the assessment process

Unjustified transfer of traditional assessment technologies to an online format

Among the risks of the first group experts named the incompleteness and one-sidedness of evaluation tools for educational programs belonging to the enlarged group "Education and pedagogical sciences", available in the electronic information and educational environment, which do not allow a comprehensive assessment of the results of vocational education $(68 \%$ of respondents). In addition the assessment funds were designed in such a way that they often did not provide for the possibility of using e-education and distance learning technologies during the assessment procedures ( $88 \%$ of respondents). $76 \%$ of respondents point to the lack of efficiency of the system content filling of the electronic information and educational environment, designed to assess the formation of competencies. Another $56 \%$ of respondents drew attention to the insufficient quality of electronic educational resources that provide the presentation of assessment tools in electronic and digital form.

Among the risks of the second group, experts pointed out the restriction of "direct" contacts of educational subjects in the course of assessing the quality of educational activities and training of students $(76 \%$ of respondents). $52 \%$ of respondents paid attention to the presence of technical problems in the implementation of assessment using electronic educational resources, another $48 \%$ note the lack of digital competence of the subjects of quality assessment and $36 \%$ of respondents point to the existing difficulties in choosing electronic educational services that ensure the implementation of assessment procedures.

Describing the risks of the third group, respondents primarily note the unjustified transfer of traditional assessment technologies to an online format (72\%) and the insignificant involvement of individual students in 
the assessment process (60\% of respondents). $44 \%$ of experts pointed to the lack of feedback, which prevents an adequate assessment of the quality of educational activities and training of future science teachers and does not allow for timely adjustments to this process.

The identified risks of transforming the assessment of the quality of educational activities of future science teachers during the pandemic were ranked by experts and they also compiled a Risk map based on assessing the probability of their occurrence (high, medium, low) and determining the consequences of these risks (minor, significant, catastrophic).

This work allowed them to formulate proposals for the transformation of the set of organizational and functional structures, norms and rules; diagnostic and evaluation procedures used in the implementation of educational programs in the areas of training related to the enlarged group "Education and pedagogical sciences".

The content aspect of the transformation of the assessment of the quality of educational activities and the training of future science teachers is associated with the need to clarify the quality criteria. It is important not only to specify the list of universal, general professional and professional competencies that reflect the achievement of students ' results in the development of the educational program, but also to update the requirements for the conditions for the implementation of educational activities that are most significant during the pandemic (resources of the electronic information and educational environment; material and technical conditions; educational and methodological support of e-education and distance educational technologies, human resources).

The content aspect of the transformation of the assessment of the quality of educational activities and the training of future science teachers should be associated with the improvement of the fund of evaluation tools, which should provide for the possibility of using e-education and distance learning technologies in the implementation of evaluation procedures, as well as ensuring the unity of normative and non-normative quality criteria.

The instrumental aspect of the transformation of the assessment of the quality of educational activities and the training of future science teachers of design involves the choice of electronic educational services that provide the implementation of assessment procedures mainly in electronic form, as well as electronic educational resources that provide the presentation of assessment tools in electronic and digital form. Modernization of electronic educational services and resources of the electronic information and educational environment will make it possible to quickly make an assessment, save digital traces of the student, containing data on its results, as well as making it possible to make operational management decisions based on this data related to the process of professional education of a particular student and the conditions for its implementation.

The technological aspect of the transformation of the assessment of the quality of educational activities and training of future science teachers is due to the selection of variable pedagogical assessment technologies for monitoring the results of professional education (a system of virtual professional tests, assessment of the results of participation in network educational and research projects, electronic cases and audio and video fragments illustrating the solution of situational problems; design and implementation of fragments of training sessions in a network format; pedagogical situations; individual tasks designed to assess the level of mastery of future teachers of professional actions within specific professional functions, etc.) In addition, the technological aspect of the transformation of the assessment of the quality of educational activities and the training of future science teachers should be associated with an increase in the involvement of the main subjects of professional education in the assessment of the quality of educational activities and training. Experts also draw attention to the need to improve organizational procedures for assessing the quality of educational activities and training future science teachers in the context of a pandemic, due to the specific sequence and frequency of procedures.

\section{DISCUSSIONS AND CONCLUSION}

The problem of assessing the quality of educational activities and training of future science teachers in general, as well as its transformation in the context of the pandemic, in particular, is developed in line with the system and competence approaches, which are the theoretical basis of the proposed concept. In the research the content and procedures for assessing the quality of educational activities and training of future science teachers are developed in sufficient depth. However in the changed conditions it is necessary to study its specifics due to the distancing of the subjects of vocational education; the use of various educational services and resources; the widespread use of information and communication technologies both for evaluation procedures and for storing the obtained data on the quality of educational activities of students in the areas of training belonging to the enlarged group "Education and pedagogical sciences", taking into account the regulatory opportunities and restrictions for the implementation of this activity.

The conducted research allowed us to develop approaches to the transformation of the assessment of the quality of educational activities and the training of future science teachers in the context of the pandemic on the basis of the concept, the theoretical foundations of which were the system and competence approaches, 
which necessitate a comprehensive transformation of its content, instrumental and technological characteristics. The implementation of the conceptual ideas of the objectivity of the assessment of the quality of educational activities; its complex nature; technological procedures; openness; unity of the regulatory criteria established by the requirements of the FSES for HE and "nonnormative" criteria, determined by consumers of educational services, will effectively solve the problems of comprehensive assessment of the quality of educational activities and training of future science teachers in the transition to distance learning during the pandemic, as well as the development of new solutions to improve the quality of teacher education in both the short and long term. The proposed technology for transforming the assessment of the quality of educational activities and training of future science teachers in the context of the pandemic, which involves the implementation of three interrelated stages preparatory, main and final, will allow Universities to improve the internal system for assessing the quality of educational activities in the main professional educational programs related to the enlarged group "Education and pedagogical sciences", as well as to modernize the external assessment of the quality of educational activities and training of students, implemented during the procedure of state accreditation of educational programs in the new conditions.

Author contributions: All authors have sufficiently contributed to the study, and agreed with the results and conclusions.

Funding: This paper has been supported by the Kazan Federal University Strategic Academic Leadership Program.

Declaration of interest: No conflict of interest is declared by authors.

\section{REFERENCES}

Abramova, S. B., \& Antonova, N. L. (2020). Online learning: new contours of students' fears and worries in the context of a pandemic. Society: Sociology, Psychology, Pedagogy, 11(79), 14-17.

Abualrob, M. M. (2019). The Role of Science Teachers in Developing the 21st Century Skills for the Elementary School Students. Interdisciplinary Journal of Environmental and Science Education, 15(1), e02206. https:/ / doi.org/10.29333/ijese/ 6368

Ali, M., \& Shastri, K. R. (2010). Implementation of total quality management in higher education. Asian Journal of Business Management, 2(1), 9-16.

Apevalova, Z. V., Gromova, L. A., Pasholikov, M. S., \& Trofimova, I. B. (2018). Integrative models of the future teachers education quality assessment. 18th PCSF 2018 Professional Culture of the Specialist of the Future: Open University Press (pp. 1428-1438). https://doi.org/10.15405/epsbs.2018.12.02.152

Arzhakova, M. I., \& Egorova, K. E. (2021). Assessment of professional competence of future teachers of chemistry in modern conditions. Pedagogy and Education, 1, 25-35. https://doi.org/10.7256/24540676.2021.1.34367

Barmatina, I. V., \& Varakuta, A. A. (2020). Evaluation of the quality of educational activities of the university and the training of students. Bulletin of Pedagogical Innovations, 4(60), 15-22.

Bodryakov, V. U., \& Voronina, L. V. (2018). Problems of the quality of mathematical education in a pedagogical university and ways to solve them. Pedagogical Education in Russia, 2, 15-27. https: / / doi.org/10.26170/po18-02-02

Domjanić Drozdek, S., Feher Turković, L., Mojsović Ćuić, A., \& Digula, O. (2020). The Role of the iPad Tablet in Higher Education Science Teaching. Pedagogical Research, 5(1), em0051. https:/ / doi.org/10.29333/pr/6339

Galchenko, N. A., Shatskaya, I. I., Makarova, E. V., Kulesh, E. V., Nizamutdinova, S. M., Yudina, A. M. \& Skutelnik, O. A. (2020). Student hood spiritual needs in self-isolation period: Features and ways to meet them. EurAsian Journal of BioSciences, 14(1), 2229-2234.

Georgiou, M., Ziogka, K., \& Galani, L. (2020). Are PreService Teachers Ready to Write Stories in the Sciences?. Interdisciplinary Journal of Environmental and Science Education, 16(4), e2220. https:/ / doi.org/10.29333/ijese/ 8421

Gimaliev, V. G., Prokopyev, A. I., Vershinin, V. P., Ivanova, M. E., Erkibaeva, G. G., Aytuganova, J. I., \& Alexandrova, N. S. (2020). Public relations in organizations in student view: Accumulator of management tools or formation of partnership and friendly relations. Journal of environmental treatment techniques, 8(4), 1326-1330. https://doi.org/ $10.47277 /$ JETT/8(4)1230

Golovina, I. V., \& Alexandrova, T. Y. (2020). Quality of higher education: an inside look. Science and education: economy and economics; entrepreneurship; law and management, 4(119), 63-67.

Grunt, E. V., Belyaeva, E. A., \& Lissitsa, S. (2020). Distance education in the context of a pandemic: new challenges to Russian higher education. Prospects of Science and Education, 5(47), 45-58. https:/ / doi.org/10.32744/pse.2020.5.3

Khodyreva, E. A. (2020). Assessment of the quality of educational activities and training of students in the context of digital transformation of higher education. Social processes of modern Russia: Collection of materials of the International scientific and practical conference (pp. 48-53). N. Novgorod.

Klyagin, A. V., Abalmasova, E. S., Garev, K. V., Gruzdev, I. A., Egorov, A. A., Zakharova, U. S., Kalinin, R. G., Kamaldinova, L. R., Karlov, I. A., Korneeva, I. E., Makarieva, A. Yu., Minaeva, E. A., Platonova, D. P., 
Semenova, T. V., Skokova, Yu. A., Terentyev, E. A., Frumin, I. D., Schwindt, A. N., \& Shibanova, E. Y. (2020). The storm of the first weeks: how higher education stepped into the reality of the pandemic. Higher School of Economics.

Kvon, G. M., Vaks, V. B., Kalimullin, A. M., Bayanova, A. R., Shaidullina, A. R., Dolzhikova, A. V., \& Lapidus, N. I. (2019). Developing the informational and digital environment of a university: Problem analysis and assessment. Eurasia Journal of Mathematics, Science and Technology Education, 15(10), em1767. https://doi.org/10.29333/ejmste/ 109503

Kvon, G. M., Vaks, V. B., Masalimova, A. R., Kryukova, N. I., Rod, Y. S., Shagieva, R. V., \& Khudzhatov, M. B. (2018). Risk in implementing new electronic management systems at universities. Eurasia Journal of Mathematics, Science and Technology Education, 14(3), 891-902. https:// doi.org/10.12973 / ejmste/81060

Lachkova, A. H., \& Pautova, M. A. (2016). Theoretical bases of evaluation activity in the field of education. Management of socio-economic development of regions: problems and ways of their solution: collection of scientific articles of the 6th International scientific and practical conference (pp. 147-150). University book.

Larionova, A. A., Zaitseva, N. A., Anoshina, Y. F., Gaidarenko, L. V., \& Ostroukhov, V. M. (2018). The modern paradigm of transforming the vocational education system. Astra Salvensis, 6, 436-448.

Latysheva, L. P., Skornyakova, A. U., \& Cheremnykh, E. L. (2020). Professionalizing activity of students of the mathematical faculty of the pedagogical university and methodological competence of the future teacher. Humanities and Education, 1(41), 5871.

Levina, I. D., Ukolova, L. I., Lavrentyeva, E. Y., Akhilgova, M. T., Zharikov, Y. S., Popova, O. V., Semyanov, E. V., Malanov, I. A., Muskhanova, I. V., Magomeddibirova, Z. A., Bazaeva, F. U., \& Isaeva M. A. (2019). Nursing home conditions for elderly people and its peculiarities of their adaptation. EurAsian Journal of BioSciences, 13(2), 1549-1555.

Linnik, E. P., Ovchinnikova, M. V., \& Shilova, L. I. (2020). Pros and cons of using distance learning forms in professional and pedagogical training of future teachers of mathematics. In the collection: Information systems and technologies in modeling and management. Proceedings of the $V$ International Scientific and Practical Conference (pp. 414-417).

Lyfenko, A. V., \& Savchenko, S.V. (2017). Principles for assessing the quality of higher education. Bulletin of the Kaluga University, 1, 69-71.

Okhlupina, O. V. (2020). Universities facing a pandemic: actual aspects of the organization of independent work of students in the conditions of distance learning. Higher Education Today, 7, 24-28. https:/ / doi.org/10.25586/RNU.HET.20.07.P.24

Permyakov, O. E. (2005). Methodological approaches to the design of educational quality assessment systems. Proceedings of the Tomsk Polytechnic University. National Research Tomsk Polytechnic University, 4, 221-225. https://cyberleninka.ru/ article/n/metodologicheskie-podhody-k-proekti rovaniyu-sistem-otsenki-kachestva-obrazovaniya

Potapova, S. V., Danilova, I. Y., Prasolov, V. I., Makarova, E. V., \& Kryukova, N. I. (2018). Mythological foundations of ontology. XLinguae, 11(2), 672-685. https://doi.org/10.18355/XL.2018. 11.02 .53

Razumovskaya, M., Zaitseva, N. A., Larionova, A. A., Chudnovskiy, A. D., \& Breusova, E. A. (2018). Prospects for applying various forms of organizational integration to improve the quality of education. Astra Salvensis, 6, 348-362.

Ruban, E. M., Gordeeva, I. A., \& Lekomtsev, A. A. Optimization and evaluation of the effectiveness of distance learning of professional training of bachelors of education-future science teachers in a pedagogical University in the context of the COVID-19 pandemic. Modern Scientist, 5, 118-123.

Safronova, O. V., Dyakova, O. V., \& Vedler, O. V. (2020). The system for assessing the quality of education at different levels of training: principles and structure. Science, education, innovations: topical issues and modern aspects: collection of articles of the IV International scientific and practical conference (pp. 164-166). Science and Education.

Shinkevich, M. V., Mashkin, N. A., Ishmuradova, I. I., Kolosova, V. V., \& Popova, O. V. (2020). Management of sustainable consumption of energy resources in the conditions of digital transformation of the industrial complex. International Journal of Energy Economics and Policy, 10(5), 454-460. https://doi.org/10.32479/ijeep. 10202

Smirnova, A. S. (2020). Organization of distance learning of students in the context of a pandemic. Bulletin of the Amur State University of Sholom-Aleichem, 4(41), 93-100. https://doi.org/10.24412/2227-1384-20204-93-100

Sokolovskaya, I. E. (2020). Socio-psychological factors of student satisfaction in the context of digitalization of education during the COVID-19 pandemic and self-isolation. Digital Sociology, 2, 46-54. https: / / doi.org/10.26425/2658-347X-2020-2-46-54

Trapitsin, S., Granichina, O., \& Granichin, O. (2017). Information and mathematical models for evaluation of the effectiveness and quality of the University. International Conference "Quality 
Management, Transport and Information Security, Information Technologies". IT and QM and IS, 10, 287291.

https://doi.org/10.1109/ITMQIS.2018.8524943

Trškan, D. (2017). Quality indicators, a new method for the evaluation of teaching practice in teacher education programmes in Slovenia: an example of quality indicators for school mentors - external mentors. Revista Electrónica Interuniversitaria de Formación delProfesorado, 20(2), 63-77. https:/ / doi.org/10.6018/reifop.20.1.273871

Tugun, V., Bayanova, A. R., Erdyneeva, K. G., Mashkin N. A., Sakhipova, Z. M., \& Zasova, L. V. (2020). The opinions of technology supported education of university students. International Journal of Emerging Technologies in Learning, 15(23), 4-14. https://doi.org/10.3991/ijet.v15i23.18779

Usak, M., Masalimova, A. R., Cherdymova, E. I., \& Shaidullina, A.R. (2020). New playmaker in science education: COVID-19. Journal of Baltic Science Education, 19(2), 180-185. https://doi.org/10.33225 /jbse/20.19.180

Weindorf-Sysoeva, M. E., \& Subocheva, M. L. (2020). Distance learning in the context of a pandemic: Problems and ways to overcome them. Problems of Modern Pedagogical Education, 67(4), 70-74.

Yermilova, V. V., Loktionova, Y. N., Smirnov, A. V., Seregina, T. N., \& Prokopyev, A. I. (2019). The development of a personal wellbeing index indicator of the life satisfaction. Espacios, 40(25), Article number 16.

Zheltukhina, M. R., Slyshkin, G. G., Ponomarenko, E. B., Busygina, M. V., \& Omelchenko, A. V. (2016). Role of media rumors in the modern society. International Journal of Environmental and Science Education, 11(17), 10581-10589.

\section{http://www.ejmste.com}

